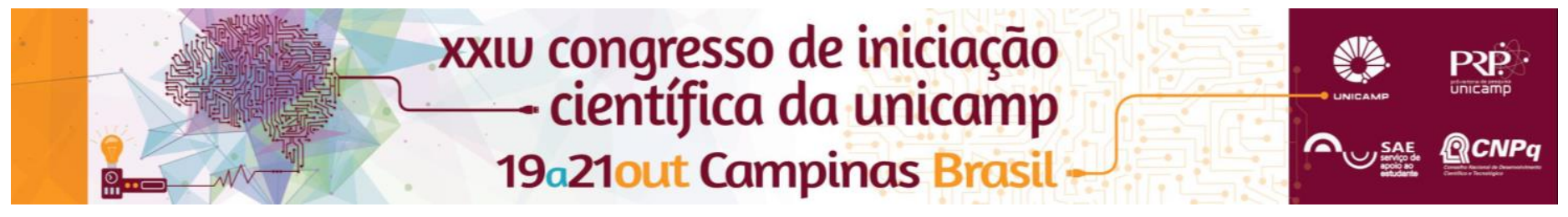

\title{
EXPLORAÇÃO DE ESTRATÉGIAS DE MELHORIA NA CINÉTICA DE LIBERAÇÃO DE ALPHASAN® RC2000 INCORPORADO EM MEMBRANAS DE QUITOSANA E ALGINATO
}

\author{
Amanda Piton de Araujo*, Ana Luiza Resende Pires, Ângela Maria Moraes
}

\section{Resumo}

Filmes preparados pela complexação de quitosana $(Q)$ e alginato $(A)$ vêm sendo amplamente estudados para a confecção de curativos. Este trabalho teve por meta investigar a factibilidade de incorporação de um agente antimicrobiano à base de prata, o AlphaSan ${ }^{\circ} \mathrm{RC} 2000$, em matrizes densas e porosas neutralizadas de $\mathrm{Q}$ e $\mathrm{A}$, rígidas ou flexíveis, e comparar a liberação do composto e outras características relevantes das matrizes, visando obter formulações atrativas para a produção em escala comercial.

\section{Palavras-chave:}

quitosana, alginato, prata.

\section{Introdução}

A quitosana e o alginato são polissacarídeos que, quando complexados, formam membranas finas, transparentes e estáveis consideradas como promissoras para utilização como curativos ${ }^{1}$. Tais membranas podem ser produzidas tanto na forma densa quanto porosa, sendo os poros resultantes da adição de tensoativos como o Kolliphor $^{\circledR}$ P188 $(\mathrm{P})$, durante o preparo do dispositivo ${ }^{2}$. Como limitadas propriedades mecânicas são verificadas para tais membranas, a adição à mistura do polímero à base de silicone Silpuran ${ }^{\circledR} 2130$ A/B (S) à solução polissacarídica vem sendo investigada ${ }^{3}$. O presente trabalho visou a incorporação do antimicrobiano contendo prata AlphaSan ${ }^{\circledR}$ RC2000 ( $\alpha$-San) nas membranas de QA contendo ou não $P$ e $S$ isolados ou em conjunto (PS) e a análise das características das membranas resultantes.

\section{Resultados e Discussão}

As membranas foram produzidas e caracterizadas com base em Bueno e Moraes ${ }^{2}$ e Pires e Moraes ${ }^{3}$.

Os aspectos visuais típicos dos filmes de QA produzidos pela adição de $10 \%(\mathrm{~m} / \mathrm{m})$ de $S(Q A S), 10 \%(\mathrm{~m} / \mathrm{m})$ de $P$ (QAP) e PS (QAPS) obtidos na ausência ou presença de $11 \%$ de $\alpha$-San $(\mathrm{m} / \mathrm{m})$ são mostrados na Figura 1.

Todas as formulações apresentaram aspecto homogêneo. As membranas de QA e QAS eram significativamente mais transparentes que as outras, devido aos poros resultantes da adição do tensoativo. As membranas contendo $\alpha$-San apresentaram aspecto esbranquiçado, com distribuição relativamente uniforme do composto, apesar de sua limitada solubilidade em soluções aquosas.

$\mathrm{Na}$ Tabela 2 são mostrados os dados de espessura das amostras secas, da capacidade de absorção em tampão fosfato-salino (PBS) e da liberação de prata em solução.

Figura 1. Aspecto visual das membranas de QA, QAS, QAP, QAPS contendo ou não $\alpha$-San.

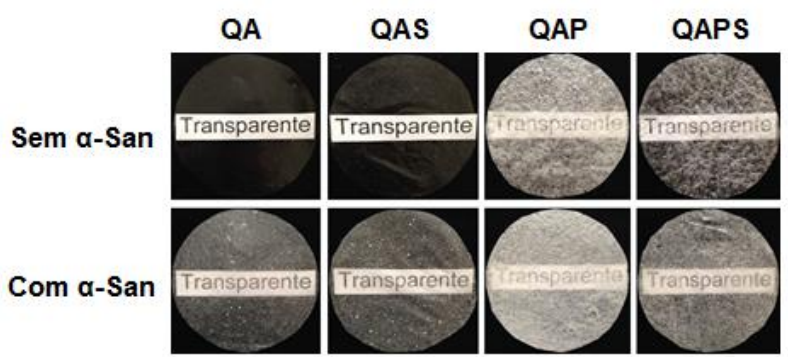

Tabela 2. Espessura das membranas secas, absorção e liberação de prata em PBS após $24 \mathrm{~h}$ em $37^{\circ} \mathrm{C}$.

\begin{tabular}{|c|c|c|c|}
\hline Formulação & $\begin{array}{c}\text { Espessura } \\
(\mu \mathrm{m})\end{array}$ & $\begin{array}{c}\text { Absorção } \\
(\mathrm{g} / \mathrm{g})\end{array}$ & $\begin{array}{c}\text { Prata } \\
\text { liberada (\%) }\end{array}$ \\
\hline QA & $56,7 \pm 9,0^{a}$ & $11,9 \pm 2,0^{a}$ & - \\
\hline QAS & $54.4 \pm 0.6^{b}$ & $7.8 \pm 1.6^{b}$ & - \\
\hline QAP & $193,4 \pm 6,4^{c}$ & $19,4 \pm 1,8^{c}$ & - \\
\hline QAPS & $179,4 \pm 4,8^{d}$ & $8,7 \pm 0,3 \mathrm{a}, \mathrm{b}$ & - \\
\hline QA $\alpha-S a n$ & $124,6 \pm 2,3^{\mathrm{e}}$ & $8,5 \pm 1,1$ a,b & $82,4 \pm 8,5^{a}$ \\
\hline QAS a-San & $112,4 \pm 1,8^{f}$ & $11,0 \pm 0,3^{a, b}$ & $100 \pm 0^{b}$ \\
\hline QAP $\alpha-S a n$ & $159,6 \pm 8,1 \mathrm{~g}$ & $11,9 \pm 1,4^{a}$ & $98,8 \pm 5,1^{b}$ \\
\hline QAPS $\alpha-S a n$ & $135,4 \pm 2,5 \mathrm{~h}$ & $7,5 \pm 0,7^{b}$ & $100 \pm 0 b$ \\
\hline
\end{tabular}

Mesma letra na mesma coluna indica que não há diferença significativa entre os valores médios (teste de Tukey, $p<0,05$ ).

Os valores de espessura das amostras foram menores quando na presença de $S$. Isto se deve à maior compactação entre as lamelas dos dispositivos ${ }^{3}$. As membranas porosas, tanto na presença quanto na ausência de a-San, apresentaram maiores valores de espessura e absorção em PBS, devido à presença dos poros. Já as formulações contendo $S$ absorveram menores quantidades deste fluido devido ao caráter hidrofóbico do agente siliconado, que dificulta a entrada de soluções aquosas entre as cadeias poliméricas. As eficiências de liberação foram elevadas, mostrando-se mais altas para todas as formulações contendo $S$ e $P$ em relação à $Q A$.

\section{Conclusões}

Os filmes densos mostraram-se mais transparentes que os porosos e as membranas contendo $\alpha$-San apresentaram aspecto esbranquiçado. A espessura diminuiu na presença de $\mathrm{S}$ e aumentou com a presença de poros. Os maiores valores de absorção foram obtidos para as formulações contendo $P$, tanto na presença quanto na ausência de $\alpha$ San. Notou-se alta eficiência de liberação de prata para todas as formulações após $24 \mathrm{~h}$, em especial para QAS, QAP e QAPS.

\section{Agradecimentos}

Agradecemos o suporte do CNPq a este trabalho.

${ }^{1}$ Verma, D.; Katti, K. S.; Katti, D. R. An. Biom. Eng. 2011, 36, 1024

2 Bueno, C. Z.; Moraes, A. M. J. Appl. Polym. Sci. 2011, 122, 624

${ }^{3}$ Pires, A. L. R.; Moraes, A. M. J. Appl. Polym. Sci. 2015, 132, 1. 